\title{
Wind Driven Rain (WDR) Laboratory Tests on Cavity Wall Specimens treated with surface waterproofing products
}

\author{
Henry Zhu ${ }^{\mathrm{a}, \mathrm{b}}$, Dina D’Ayala ${ }^{\mathrm{a}}$, Yasemin D Aktas ${ }^{\mathrm{a}, \mathrm{b}}$ \\ a Department of Civil Environmental and Geomatic Engineering (CEGE),UCL, London, UK \\ b UK Centre for Moisture in Buildings (UKCMB), London, UK
}

\begin{abstract}
Wind driven rain (WDR) is one of the most common sources of moisture risks affecting buildings in the UK. Water penetration can lead to defects such as ineffective insulation, damp inner walls and freeze-thaw damage, causing issues in both energy efficiency and wall integrity. Surface waterproofing products have shown great potential as a new method of improving the moisture condition in buildings. This paper is focused on real size cavity walls tested under WDR exposure to study the hygrothermal performance of surface waterproofing products. Test results show both acrylic-based liquid and silane/siloxane blend cream products were capable of lessening moisture enrichment of masonry cavity walls under cyclic WDR loading.
\end{abstract}

Peer-review under the responsibility of the organizing committee of the ICMB21.

Keywords: waterproofing, water repellence, surface treatment, brick masonry, absorption, wind-driven rain (WDR)

\section{Introduction/Background}

Moisture risk and damages are among the most common issues in building systems, which can impact on the hygrothermal performance and durability of building envelopes. Among the sources of moisture risks affecting buildings in the UK, wind driven rain (WDR) is one of the most common sources. Surface waterproofing products available in the market have shown great potential as a new method of improving the moisture condition in buildings by enhancing the hygric performance of masonry facades under water exposure, however, the extent of which they can improve the hygrothermal performance of cavity masonry walls has not been well established. This study aims to quantify the water ingress reduction in surface waterproofing-treated cavity masonry walls under WDR exposure through lab work. For the surface treatment, a commercially widely available acrylic-based product and a silane/siloxane blend cream product were used.

The WDR tests were carried out at the UCL CEGE integrated environmental-mechanical testing system composed of two climate chambers used to simulate indoor and outdoor conditions simultaneously (Fig 1). The rain system used for this study is composed of a built-in rain simulation system equipped with $18 \times 60^{\circ}$ nozzles arranged in the form of 3 rows within a portable frame, which is then positioned in front of horizontal fans to provide a wind speed equal to $3 \mathrm{~m} / \mathrm{s}$ at the nozzles, such that an average of $450 \mathrm{ml}$ of water was dispersed on 3 gauges over $400 \mathrm{~cm}^{2}$ surface area over 5 minutes. Based on this, the amount of rain dispersed on each wall can be calculated as $2.25 \mathrm{~L} / \mathrm{m}^{2} / \mathrm{min}$, which compares well with the water application in ASTM E 514/C1601 (2014).
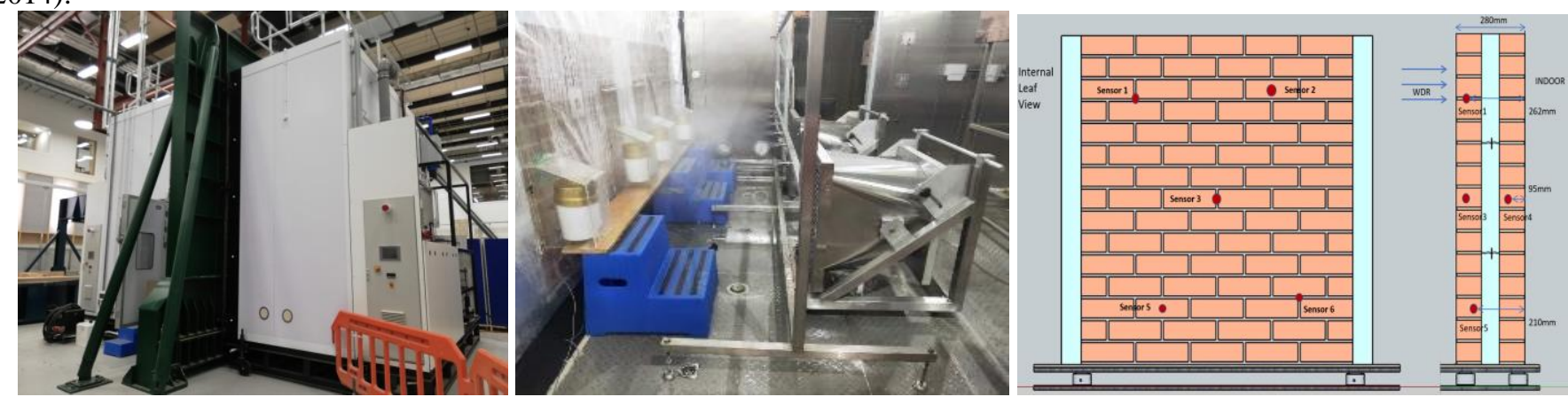

Figure 1: (from left to right) UCL CEGE integrated environmental-mechanical testing system at Here East; walls under WDR exposure; sensors locations

2 walls built in dimensions $1.1 \mathrm{~m} \times 1.1 \mathrm{~m} \times 0.28 \mathrm{~m}$, with two leaves of bricks selected from the joint paper[1], built in stretcher bond and $75 \mathrm{~mm}$ cavity in between were tested simultaneously with the 6 in-wall sensors to monitor T and RH variations. $1.4 \mathrm{~kg}$ of Polypearl Platinum polystyrene beads were poured into each cavity without use of adhesives, compacted until full. For the WDR test duration, the $\mathrm{T}$ was set at $15^{\circ} \mathrm{C}$ in the external chamber and $20^{\circ} \mathrm{C}$ in the internal chamber. Each wetting and drying cycle consists of $20 \mathrm{~min}$ wetting and 40 min drying. The flow rate of rainwater was controlled at $9 \mathrm{~L} / \mathrm{min}$ by a flowmeter at the inlet of the water to the wind-driven rain system. On the first day of the test, 2 cycles were applied to the walls. The walls were then dried overnight for 14 hours at $20^{\circ} \mathrm{C}$ in both chambers. On the second day, up to 8 more cycles were applied or the test was concluded when water penetrated the walls' cavities and was observable on the surface of the interior leaf. 


\section{Test Results and Findings}

Figure 2 provides the variation of in wall temperature and RH for the untreated wall (curve A) and one of the selected waterproofing product treated wall (curve B) before and after installed insulation. Compared with the results from the uninsulated test, slower RH gain and lower final RH readings can be witnessed on all sensor readings on the B-treated wall in the insulated test. In the first 2 wetting cycles, the RH gain on the treated wall mortar sensor has decreased from $15 \%$ in the uninsulated test to $2 \%$ in the insulated test, while on brick sensors the RH gain decreased from $6 \%$ to $1 \%$.On the other hand, both sensors in brick and mortar of the untreated wall have shown readings corresponding to the saturation of the sensors in the range of $100 \% \mathrm{RH}$, similarly to the uninsulated. During the overnight dry conditions, while the untreated wall was maintaining its RH readings on both uninsulated and insulated conditions, a further increase of $13 \%$ was observed on the mortar RH sensor for uninsulated wall B and $11 \%$ on the insulated wall B. But the brick sensor in the insulated test, RH showed an increase of $5 \%$ in the first $5 \mathrm{~h}$ and then decreased by $6 \%$, resulting in a $1 \% \mathrm{RH}$ decrease at the end of overnight drying compared to the stable $10 \%$ increase in the uninsulated test. The temperature difference between $\mathrm{B}$ and A wall increased by up to $5{ }^{\circ} \mathrm{C}$ on both brick and mortar sensors during the overnight dry conditions in the insulated test while the difference was just $2{ }^{\circ} \mathrm{C}$ in the uninsulated test. The 8 cycles on the second day did not have much impact on the total RH reading for the untreated wall in both tests, while the B-treated mortar and brick show a steady increase of $10 \%$ in the insulated test. In the uninsulated test, mortar in wall B had a low increase of $1 \%$ and brick showed no increase in the first three cycles but then an increase of $12 \%$ during the following five cycles. The sensors on the interior leaf of both walls in uninsulated test had a gain of $13 \% \mathrm{RH}$ over the whole test with a maximum difference of up to $5 \%$ in $\mathrm{RH}$ and $2{ }^{\circ} \mathrm{C}$ in $\mathrm{T}$ between the untreated wall and the B-treated wall. On the insulated test, the sensors on the interior leaf of B-treated wall had a gain of $7 \% \mathrm{RH}$ over the whole test while the untreated wall shows a $12 \% \mathrm{RH}$ gain, resulting in a difference of up to $5 \%$ in $\mathrm{RH}$ and $1{ }^{\circ} \mathrm{C}$ in $\mathrm{T}$ between the two walls.

Uninsulated
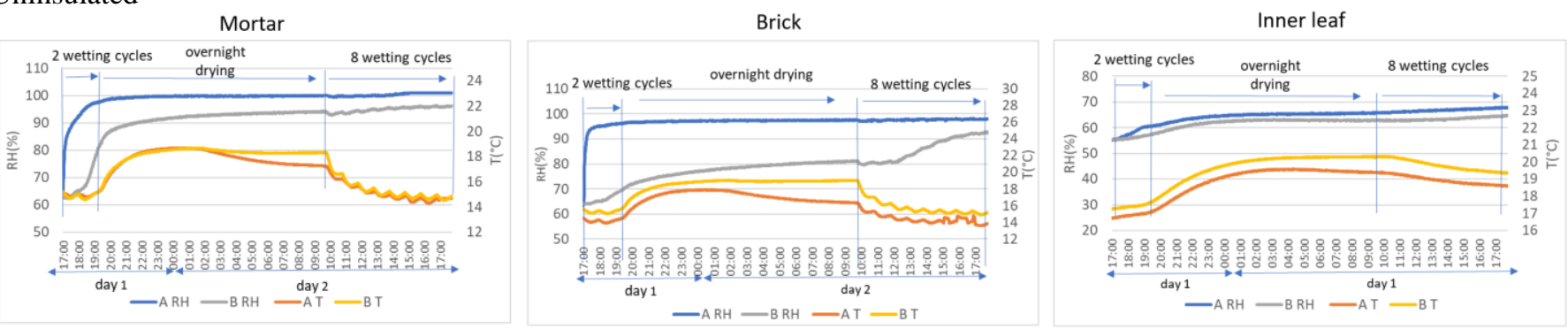

Insulated
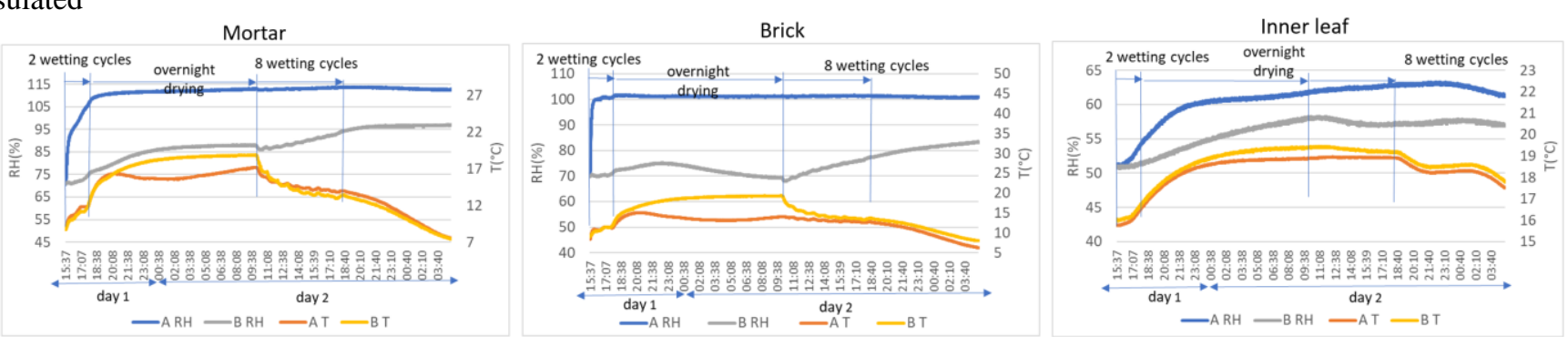

Figure 2: Variation of in-wall temperature and RH for the untreated (A) and treated (B) uninsulated (top) and insulated (bottom) walls

\section{Conclusions}

The results suggest that waterproofing agents in combination with cavity wall insulation appear to have a notable beneficial effect in reducing the water ingress of masonry cavity walls than in the uninsulated cases, provided that the wall system is in good state of conservation. This is likely to be in part a function of how the presence of the insulation changes the heat and moisture transfer across the whole wall. The overall performance change following waterproofing is positive, as both treatments were capable of lessening moisture enrichment of masonry cavity walls under cyclic wind driven rain (WDR) loading. The results show that installing insulation in cavities can improve the thermal performance of masonry cavity walls while waterproofing treatments are able to provide additional resistance to water ingress contributing to maintain the insulation dry and effective.

\section{Acknowledgements}

This work has been carried out as part of the 'Waterproofing cavity walls to allow insulation in exposed areas' project, funded by Department for Business, Energy and Industrial Strategy (BEIS), in collaboration with the UK Centre for Moisture in Buildings (UKCMB), UCL Institute for Environmental Design and Engineering (IEDE) and Building Research Establishment (BRE). The authors are grateful to BEIS and its advisory team for funding and assistance throughout. We also cordially thank BRE's Colin King and Andy Sutton, and the rest of the project team for the invaluable discussions.

\section{References}

[1] Henry Zhu, Dina D’Ayala, Yasemin D Aktas,2021. Performance Comparison of Surface Waterproofing Products with Various Chemical Compositions on Brick Masonry, ICMB21 